\title{
FUSION OF ACTIVE AND PASSIVE MICROWAVE OBSERVATIONS TO CREATE AN ESSENTIAL CLIMATE VARIABLE DATA RECORD ON SOIL MOISTURE
}

\author{
W. Wagner ${ }^{\mathrm{a},}$, , Wouter Dorigo ${ }^{\mathrm{a}}$, Richard de Jeu ${ }^{\mathrm{b}}$, Diego Fernandez ${ }^{\mathrm{c}}$, Jerome Benveniste ${ }^{\mathrm{c}}$, Eva Haas ${ }^{\mathrm{d}}$, Martin Ertl ${ }^{\mathrm{e}}$ \\ ${ }^{a}$ Vienna University of Technology, Institute of Photogrammetry and Remote Sensing, Gusshausstrasse 27-29, 1040 \\ Wien, Austria, (ww, wd)@ipf.tuwien.ac.at \\ ${ }^{\mathrm{b}}$ Vrije Universiteit Amsterdam, Department of Hydrology and Geo-environmental Sciences, De Boelelaan 1085 \\ 1081 HV Amsterdam, The Netherlands, Richard.de.jeu@falw.vu.nl \\ c European Space Agency, ESA-ESRIN, Via Galileo Galilei, 00044 Frascati, Italy, (Diego.Fernandez, \\ Jerome.Benveniste)@esa.int \\ ${ }^{d}$ GeoVille Information Systems, Sparkassenplatz 2, 6020 Innsbruck, Austria, haas@geoville.com \\ e Angewandte Wissenschaft Software und Technologie, Mariahilfer Strasse 47/3/1, 1060 Vienna, Austria, ertl@awst.at
}

Commission VII, WG VII/6

KEY WORDS: Climate, Hydrology, Fusion, Radar, Radiometry, Calibration, Change detection

\begin{abstract}
:
Soil moisture was recently included in the list of Essential Climate Variables (ECVs) that are deemed essential for IPCC (Intergovernmental Panel on Climate Change) and UNFCCC (United Nations Framework Convention on Climate Change) needs and considered feasible for global observation. ECVs data records should be as long, complete and consistent as possible, and in the case of soil moisture this means that the data record shall be based on multiple data sources, including but not limited to active (scatterometer) and passive (radiometer) microwave observations acquired preferably in the low-frequency microwave range. Among the list of sensors that can be used for this task are the C-band scatterometers on board of the ERS and METOP satellites and the multi-frequency radiometers SMMR, SSM/I, TMI, AMSR-E, and Windsat. Together, these sensors already cover a time period of more than 30 years and the question is how can observations acquired by these sensors be merged to create one consistent data record? This paper discusses on a high-level possible approaches for fusing the individual satellite data. It is argued that the best possible approach for the fusion of the different satellite data sets is to merge Level 2 soil moisture data derived from the individual satellite data records. This approach has already been demonstrated within the WACMOS project (http://wacmos.itc.nl/) funded by European Space Agency (ESA) and will be further improved within the Climate Change Initiative (CCI) programme of ESA (http://www.esa-cci.org/).
\end{abstract}

\section{INTRODUCTION}

Soil moisture is the water contained in the weathered and fragmented outer soil layer of the earth's terrestrial surface (Hillel, 1982). Because soil moisture is arguably one of the most important parameters for the understanding of physical, chemical and biological land surface processes (Legates et al., 2011) it is for many geoscientific applications essential to know how much water is stored in the soil, and how it varies in space and time. This fact was recently highlighted in a report titled „Critical Earth Observation Priorities“ published in 2010 by the Group on Earth Observation (GEO) (http://sbageotask.larc. nasa.gov). Based on an extensive survey of user needs soil moisture was ranked the second top priority parameter (behind precipitation) which is needed in all so-called GEO societal benefit areas (disasters, health, energy, climate, water, weather, ecosystems, agriculture and biodiversity). Climate change is not an exception and, in fact, long-term changes in soil moisture induced by global warming may have more drastic effect on society and nature than the warming itself. Consequently the role of soil moisture in the climate system has already been intensively investigated by the climate research community. Yet, without suitable observations to confirm or refute the insights from the numerical model experiments, this understanding remains incomplete (Seneviratne et al., 2010). Therefore, there have already been substantial efforts to develop robust remote sensing methods for soil moisture retrieval, which eventually led to the adoption of soil moisture as an Essential Climate Variable (ECV) at the 16th Session of the Global Climate Observing System (GCOS) Steering Committee in Geneva, 14-17 October 2008. This essentially means that the international scientific community is called for action to generate long-term satellite soil moisture data sets. As a result, space-related international programmes such as the Group on Earth Observation (GEO), the Committee on Earth Observation Satellites (CEOS), and the Global Energy and Water Cycle Experiment (GEWEX) have formulated work plans that address the creation and validation of long-term satellite based soil moisture records.

For many years soil moisture was considered to be only an "emergent ECV" because the retrieval of soil moisture was deemed too difficult with existing satellite sensors. Therefore, in recognition of the strong need for global soil moisture data sets, the European Space Agency (ESA) and the National Aeronautics and Space Administration (NASA) each decided to develop a dedicated satellite mission operating at $1.4 \mathrm{GHz}$ (L-band). The first mission is the Soil Moisture and Ocean

\footnotetext{
* Corresponding author.
} 
Salinity (SMOS) satellite that was launched in November 2009 by ESA (Kerr et al., 2010). The second one is NASA's Soil Moisture Active Passive (SMAP) mission that is planned for launch in the 2014/15 timeframe (Entekhabi et al., 2010a). But, as already noted by Wagner et al. (2007): "Besides these innovations in space technology, an initially less-visible revolution has taken place in algorithmic research. This revolution became possible thanks to the increasing availability of computer power, disk space, and powerful programming languages at affordable costs. This has allowed more students and researchers to develop and test scientific algorithms on regional to global scales than in the past. This has led to a greater diversity of methods and consequently more successful retrieval algorithms.”

In line with the above-described developments, several global and continental-scale soil-moisture datasets have been published and shared openly with the international community within the last decade. The very first remotely sensed global soil moisture dataset was published by the Vienna University of Technology (TU Wien) in 2002 and was based on nine years (1992-2000) of ERS C-band (5.6 GHz) scatterometer measurements (Scipal et al., 2002). NASA released its first global soil moisture data retrieved from microwave radiometer measurements using the algorithms developed by Njoku et al. (2003) in the following year. Since then several other soil moisture data mostly based on microwave radiometers (AMSR-E, Windsat, etc.) have became freely available, notably the multi-sensor soil moisture dataset produced by Vrije Universiteit Amsterdam (VUA) in cooperation with NASA (Owe et al., 2008), and the WindSat soil moisture dataset produced by the US Navel Research Laboratory (Li et al., 2010). The first operational near-real-time soil moisture service was launched by EUMETSAT in 2008 based on the METOP Advanced Scatterometer (ASCAT) and algorithms and software prototypes developed by TU Wien (Bartalis et al., 2007). Finally, SMOS soil moisture data started to become available in 2010, with first validation results published in 2011 (Albergel et al., 2011).

Having a number of independent satellite soil moisture data sets does not mean that it is straight forward to create long-term consistent time series suitable for climate change studies. In fact, for the assessment of climate change effects on soil moisture even subtle long-term trends must be detected reliably. This means that any potential influences of mission specifications, sensor degradation, drifts in calibration, and algorithmic changes must be carefully corrected for. Also, it must be guaranteed that the soil moisture data retrieved from the different active and passive microwave instruments are physically consistent.

In this paper we discuss on a high-level alternative designs of an ECV production system for generating one global and longterm soil moisture data record. This ECV production system shall meet the scientific and technical requirements as discussed in Section 2 and 3 as good as possible. The candidate approaches for fusing the different microwave data sets to generate an ECV data record will be discussed in Sections 4 and 5 , followed by a presentation of preliminary results over Australia (Section 6) and an outlook (Section 7).

\section{SCIENTIFIC REQUIREMENTS}

Thanks to the fact that several decade-long soil moisture data records have been released within the last few years the generic user requirements for ECV soil moisture data records are already reasonably well understood. According to our experience from the cooperation with users of our soil moisture data sets (Wagner et al., 2007; de Jeu et al., 2008), the most important of these are:

1. Soil moisture is preferably expressed in volumetric soil moisture units $\left(\mathrm{m}^{3} \mathrm{~m}^{-3}\right)$. If soil moisture is expressed in a different unit, the conversion rule must be specified.

2. From an application point of view the ECV data should preferably represent the soil moisture content in deeper soil layers $(0.2-1 \mathrm{~m})$, not just the thin (0.5-5 $\mathrm{cm})$ remotely sensed surface soil layer. Nevertheless, expert users typically prefer to work with data that are as close to the sensor measurements as possible, making the conversion of the remotely sensed surface soil moisture measurements to profile estimates themselves.

3. When merging datasets coming from different sensors and satellites the highest possible degree of physical consistency shall be pursued.

4. Due to the long autocorrelation length of the atmosphere-driven soil moisture field (Entin et al., 2000) a spatial resolution of $\leq 50 \mathrm{~km}$ is sufficient for climate studies.

5. The temporal sampling interval depends on the chosen soil layer. For deeper soil layers $(1 \mathrm{~m})$ a sampling rate of 1 week is in general enough, but for the thin remotely sensed soil layer it is $\leq 1$ day.

6. Having a good quantitative understanding of the spatio-temporal error field is more important than working under the assumption of arbitrarily selected accuracy thresholds (e.g. like the often cited 0.04 $\left.\mathrm{m}^{3} \mathrm{~m}^{-3}\right)$.

7. Some soil moisture applications require a good accuracy (low bias), but for most applications it is in fact more important to achieve a good precision (Koster et al., 2009; Entekhabi et al., 2010b).

8. For climate change studies the drift in the bias and dynamic range of the soil moisture retrievals should be as small as possible.

\section{SYSTEM REQUIREMENTS}

The generation of an ECV data set is not a one-off activity, but should in fact be a long-term process where the ECV product shall be continued and improved step by step with the active involvement of a broad scientific community. From a system point of view this requires that the ECV Production System is modular so that

- $\quad$ the system supports algorithm development and is most open to broad scientific participatory inputs

- algorithms can be improved while minimising reprocessing costs

- upgrades of any of its parts are facilitated without repercussions elsewhere

- the system can be moved to different operators if required, i.e. it allows adaptations to different data processing framework solutions

But not only modularity is a major requirement. The design and operations of the system should also be as lightweight as possible in order to be able to 
- $\quad$ re-process ECV data records on a frequent basis to account for Level 1 calibration- and Level 2 algorithmic updates

- $\quad$ update the ECV data sets rapidly in case of new Level 2 data sets become available

- $\quad$ test alternative error characterisation, matching and merging approaches

- $\quad$ keep operations and maintenance costs low

In remote sensing the terms "Level 1" and "Level 2" refer to the data processing level, whereas Level 1 data are geometrically corrected data in sensor units (e.g. brightness temperature, backscattering coefficient) and Level 2 data are geophysical variables (e.g. soil moisture, leaf area index) at the same resolution and location.

\section{FUSION OF LEVEL 1 MICROWAVE OBSERVATIONS}

Probably the most straight-forward approach to generating an ECV soil moisture data set would be to feed the Level 1 backscatter- and brightness temperature observations of all different active and passive microwave remote sensing instruments into one Level 2 soil moisture retrieval system, delivering as direct output a harmonised and consistent activepassive based ECV surface soil moisture data set covering the complete period from 1978 to the present (Figure 1).

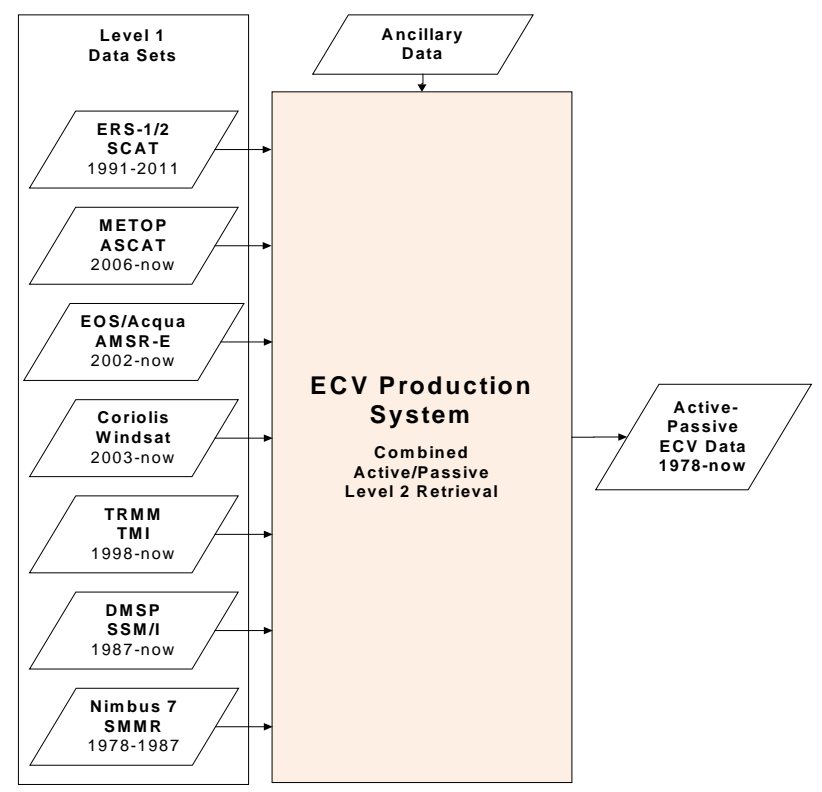

Figure 1: A potential approach for producing an ECV soil moisture data set directly from historic Level 1 backscatter- and brightness temperature data sets.

As ideal as this approach may seem from a scientific point of view, there are some major practical problems:

- The technical specifications of the diverse active and passive microwave sensors suitable to soil moisture retrieval (ASCAT, AMSR-E, SMOS, SMAP, etc.) are so different that it appears hardly feasible to design onecan-do-it-all physical retrieval algorithm.

- The complexity of the retrieval algorithm and the requirements for high-quality ancillary data to constrain the retrieval process can be expected to increase drastically for a multi-senor compared to a single-sensor Level 2 retrieval approach. This bears a certain risks of errors becoming less easily traceable. Also, the overall software system may not be scalable in terms of processing time and disk space.

- For much of the historic time period (1978-2007) the spatio-temporal overlap of suitable active and passive microwave measurements is minimal.

- Because the surface soil moisture content may vary within minutes to hours, combing measurements taken at different times of the day in multi-sensor approach may produce large errors. It can e.g. be noted that the measurements of ASCAT (9:30 and 21:30 local time), AMSR-E (1:30 and 13:30) and SMOS (6:00 and 18:00) are currently well spread over the complete day.

Each one of these problems is serious enough not to consider an ECV Production System based on the fusion of Level 1 microwave observations. Considered together one can conclude that such an ECV Production system would neither be modular nor lightweight (cf. Section 3), which makes this approach technically intractable. Therefore, in the next section the fusion of Level 2 soil moisture retrievals is discussed.

\section{FUSION OF LEVEL 2 SOIL MOISTURE RETRIEVALS}

The generation of an ECV soil moisture data set based on Level 2 soil moisture retrievals involves the following steps (Figure 2):

1. Level 2 soil moisture retrieval is done for each satellite data set separately

2. Fusion of the active Level 2 data sets

3. Fusion of the passive Level 2 data sets

4. Fusion of the merged active and passive data sets from steps 2 and 3

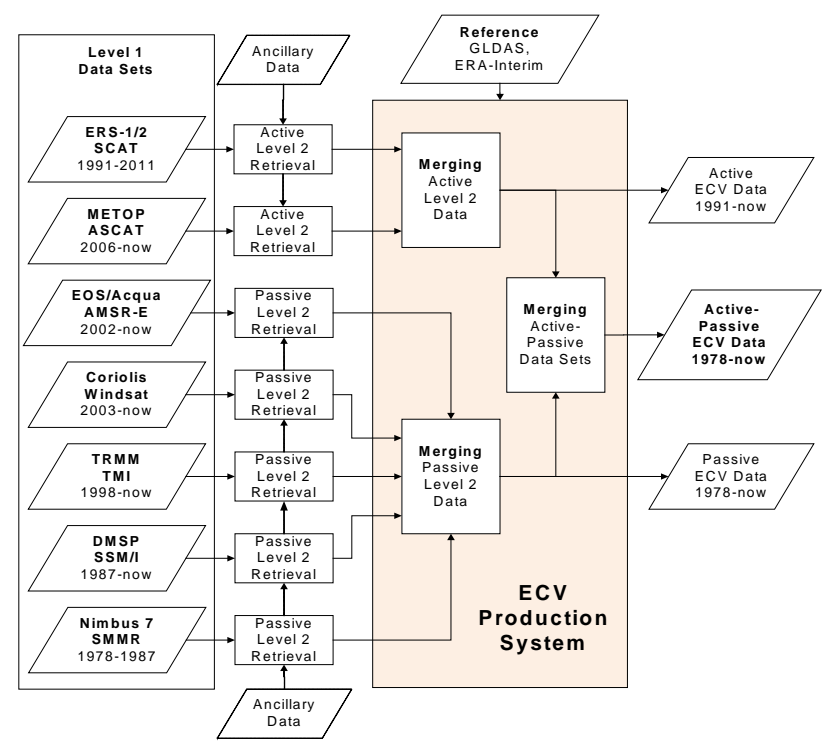

Figure 2: Flow chart of the ECV Production System as first proposed in the ESA funded WACMOS project (Dorigo et al., 2010; Liu et al., 2011).

In this approach the three important steps in the fusion process are: 1) error characterisation, 2) matching to account for data set specific biases, and 3) merging. The major advantage of this 
approach is that it allows combining surface soil moisture data derived from different microwave remote sensing instruments with substantially different instrument characteristics. It is only required that the retrieved Level 2 surface soil moisture data pass pre-defined quality criteria. In this way it is guaranteed that no sensor is a priori excluded by this approach. It is thus straight forward to further enrich the ECV data set with Level 2 data from other existing (SMOS, radar altimeters, ...) and forthcoming (Aquarius, SMAP, ...) sensors.

In this approach the ECV Production System does, per se, not need to include the different Level 2 processors. In other words, the different Level 2 baseline data can be provided by the expert teams for the different sensor types (scatterometers, multi-frequency radiometers, SMOS, SMAP, etc.) and the ECV Production System itself has to deal with the fusion process only, as described above. This design is modular and lightweight, meeting the requirements as discussed in Section 3.

A simplification of the ECV Production System as shown in Figure 2 can be achieved if the existing Level 1 inter-calibration biases of the different microwave instruments can be quantified and hence be removed. For example, the current Level 1 bias between ERS SCAT and METOP ASCAT is in the order of about 0.1-0.3 dB and variable over the incidence angle range (Bartalis et al., 2010). Such a bias may cause differences in the soil moisture estimates of more than $10 \%$ (over areas with a low sensitivity to soil moisture). Work is underway to quantify the bias between the latest version of the ASCAT calibration (Wilson et al., 2010) and the one of the ERS Level 1 archive reprocessed with an advanced scatterometer software (Crapolicchio et al., 2004). It is expected that the updated biascorrection tables will become available within the next two year, after which it will be possible to feed the Level 1 backscatter data of both ERS SCAT and METOP ASCAT into a Level 2 processor to produce directly a harmonized active ECV data set (Figure 3). A similar simplification may in principle be possible also for the passive multi-frequency radiometers, but due to much more significant differences in design and operations of the instruments, this appears unrealistic within the near future.

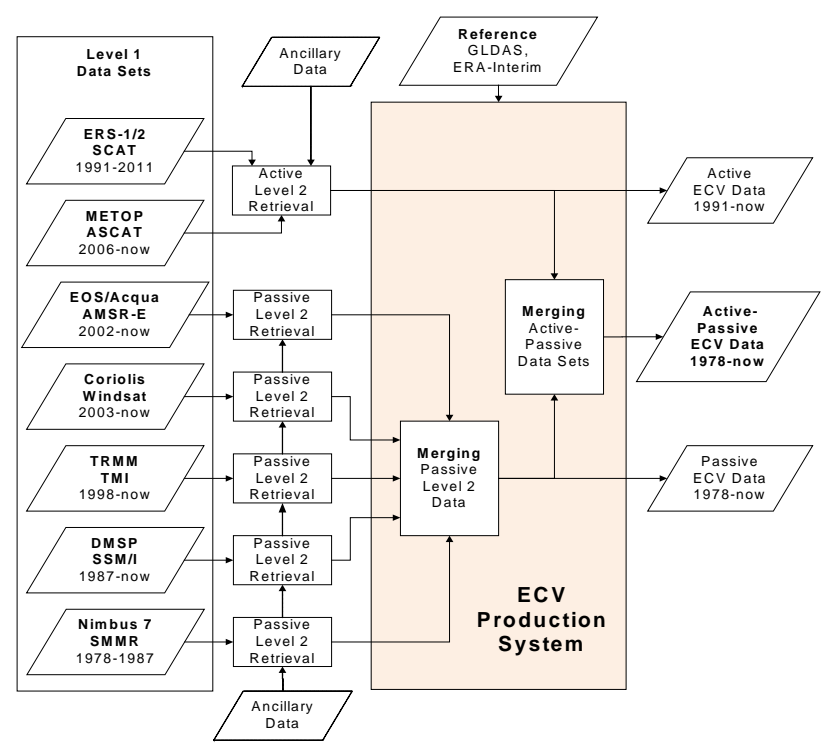

Figure 3: Flow chart of the ECV Production System in case that the current Level 1 inter-calibration biases between ERS SCAT and METOP ASCAT can be quantified and removed.
The most serious concern related to this fusion approach is that Level 1 data processed with different Level 2 algorithms may not represent the same physical quantity. Fortunately, as an increasing number of validation and inter-comparison studies show (Rüdiger et al., 2009; Gruhier et al., 2010; Brocca et al., 2011; Albergel et al., 2012), the temporal soil moisture retrieval skills of SMOS, ASCAT, AMSR-E are comparable and of good quality in regions with sparse to moderate vegetation cover. Therefore, after bias correction and - if necessary - conversion of units, the different Level 2 soil moisture data sets can be merged. Nevertheless, to maximise physical consistency it is advisable to process all active microwave data sets as shown in Figure 3 with one algorithm, and all passive microwave data with another algorithm. In other words, for groups of sensors with comparable sensor characteristics (scatterometers, multifrequency radiometers) one should select only one algorithm.

Nevertheless, depending on the relative performance of the active and passive retrieval algorithms, the combined active (scatterometer) and passive (multi-frequency radiometer) data sets may not always be directly comparable. Therefore, as illustrated in Figure 2 and Figure 3, the ECV Production System will deliver, besides the fused and thus most complete active/passive ECV data set, the two active-only and passiveonly ECV data sets. It will be thus up to the user to decide, which of these ECV soil moisture data sets is best suited for his or her analyses.

\section{FIRST RESULTS}

The Level 2 data fusion approach as discussed in the previous section has already been implemented and tested within the ESA funded WACMOS project (Su et al., 2010). The goal of the project was to produce the first $30+$ years soil moisture data set by merging active (ERS SCAT and METOP ASCAT) and passive (SMMR, SSM/I, TMI, and AMSR-E) soil moisture retrievals. This data set will be released in April 2012 and can be obtained from the authors of this paper.

First results of the WACMOS project were reported by Dorigo et al. (2010) who used the novel triple collocation method (Scipal et al., 2008; Miralles et al., 2010) for characterising the spatially variable error field of active (ASCAT) and passive (AMSR-E and SSM/I) soil moisture retrievals. The knowledge of the spatial error field allows identifying areas where none (e.g. over tropical forest where the microwaves do not penetrate the dense canopy), one (e.g. over desert areas where only the passive microwave retrievals are currently of good quality) or more (over grassland and agricultural areas where all satellite retrievals are of good quality) satellite data sets are used as input to the fusion process. The fusion algorithm itself was first presented by Liu et al. (2011) who merged AMSR-E and ASCAT soil moisture retrievals for the year 2007. They found that the merging process improved the spatio-temporal coverage while minimally impacting the accuracy of the soil moisture retrievals.

For scaling the measurements of individual passive and active sensors into a common climatology, AMSR-E and ASCATbased soil moisture products, respectively, are used as a reference since they are known to provide the most reliable climatology for the individual product groups. As neither of the product groups provides a global coverage a supplementary dataset is needed to scale merged active and passive datasets into globally consistent climatology. For the WACMOS product this reference is provided by the GLDAS-Noah data 
assimilation system (Rodell et al., 2004). Scaling is performed using cumulative distribution function (CDF) matching (Reichle et al., 2004; Drusch et al., 2005).

Preliminary results for Australia are reported in the following. Australia was gripped by the most severe drought in living memory, the so-called "Big Dry" from about 1995 to 2009 (Ummenhofer et al., 2009). Around the year 2010 the conditions switched from dry to wet particularly in the eastern parts of Australia, with some severe flood events occurring in 2010 and 2011 (e.g. the Queensland floods in December 2010 and January 2011). Such extreme conditions can be best represented by calculating seasonal or yearly anomalies based on the long-term soil moisture time series. For example, Figure 4 shows the seasonal anomalies March-May 2010 and September-November 2010 against the 1979-2010 mean, illustrating the extremely wet conditions in eastern Australia in 2010.

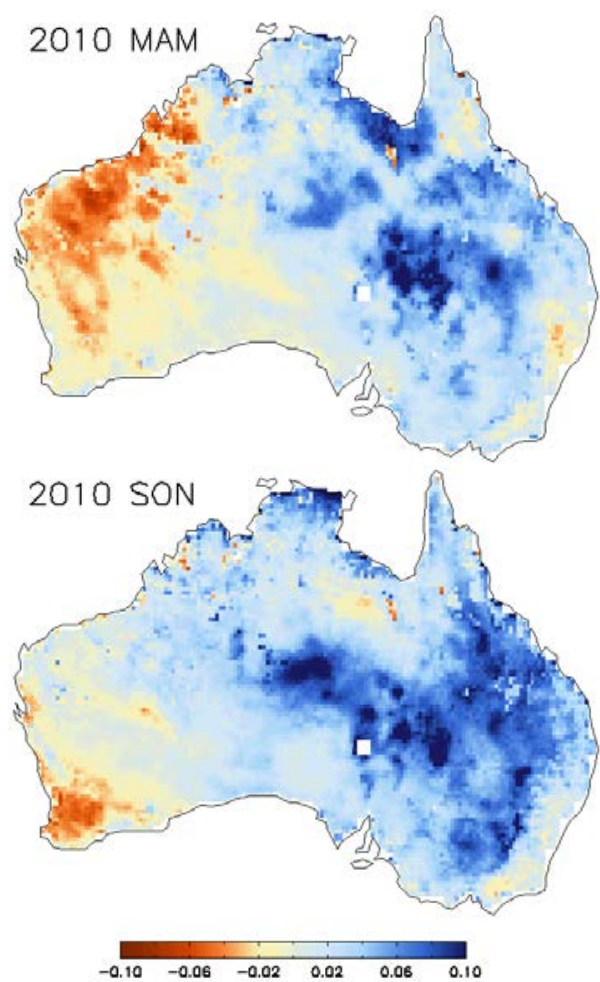

Figure 4: Seasonal soil moisture anomalies over Australia for March-May 2010 and September-November 2010.

Yearly soil moisture anomalies for the period 1979-2010 have been calculated for four different regions in Australia. The four regions are situated in the north west (NW), north east (NE), south east (SE) and south west (SW) of Australia as illustrated in Figure 5. As one can see in Figure 6 the long-term soil moisture dynamics behave very differently for these regions; the variability is highest in the NW region, becoming progressively dampened in the NE, SE, and SW study sites. In terms of the anomalies, the "Big Dry" was most pronounced over the two eastern study areas. However, also over the SW study sites the (smaller) negative soil moisture anomalies since 2000 proved problematic given the overall more arid character of this part of Australia. Figure 6 also illustrates the abrupt change from dry to wet in the eastern part of Australia in 2010; the strength of the 2010 (wet) anomaly was truly exceptional over the two eastern study sites.

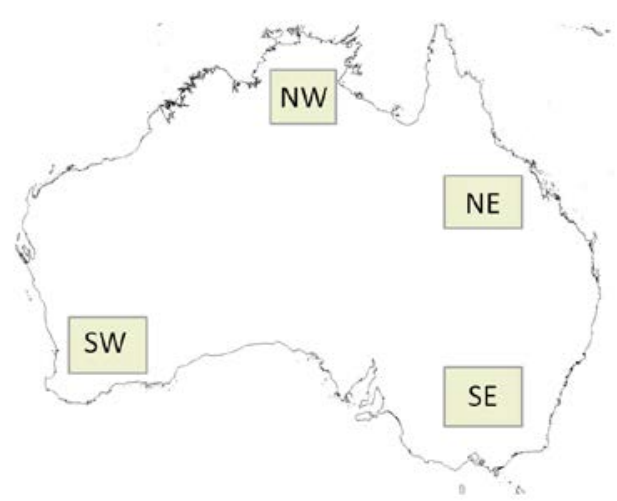

Figure 5: Location of the four study sites in Australia, denoted by NW (North West), NE (North East), SE (South East) and SE (South West).

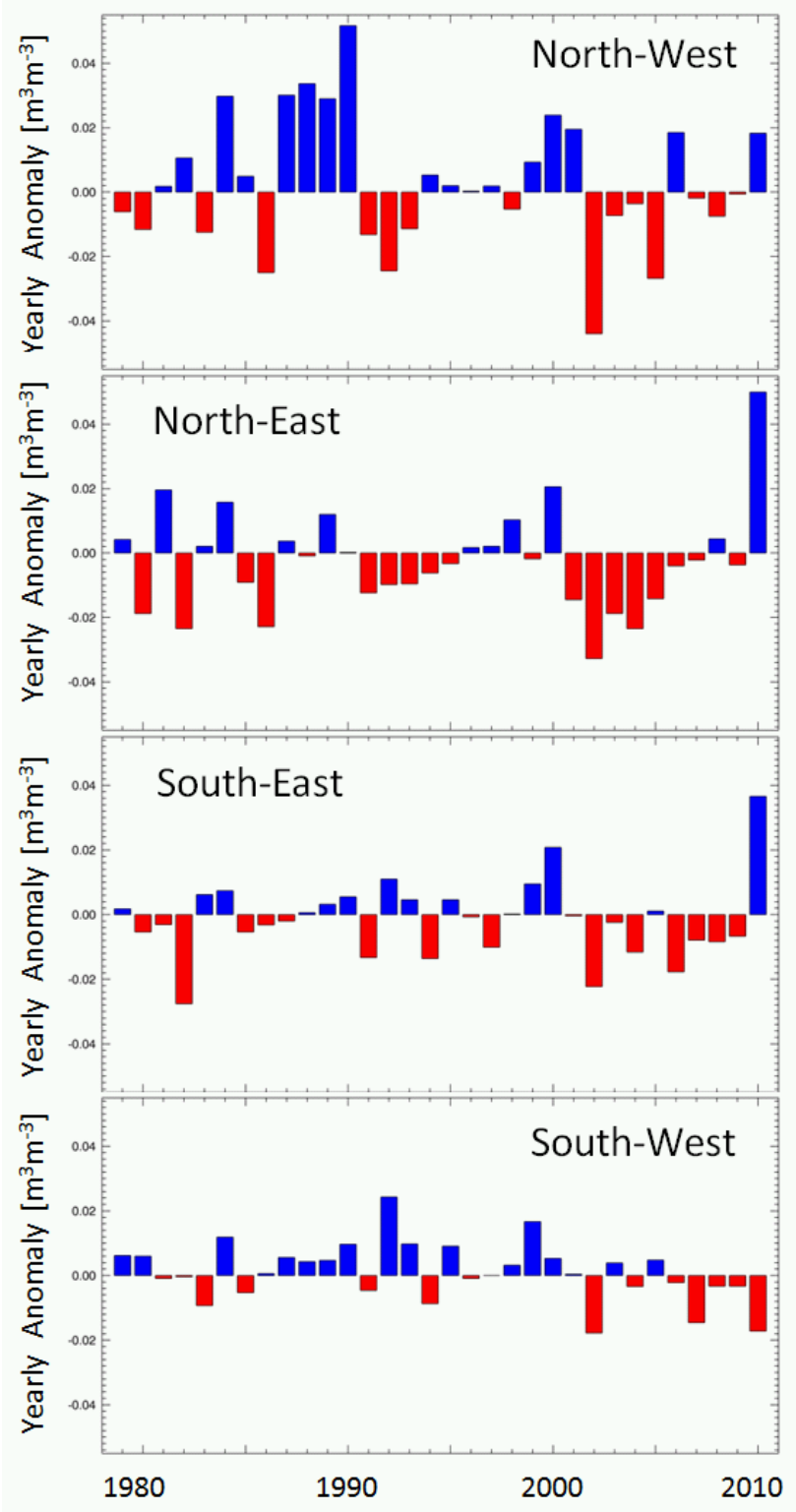

Figure 6: Time series of yearly soil moisture anomalies expressed in volumetric soil moisture units $\left[\mathrm{m}^{3} \mathrm{~m}^{-3}\right]$ for the period 1979-2010 over the four regions in Australia as indicated in Figure 5. 


\section{OUTLOOK}

The WACMOS project (http://wacmos.itc.nl/) succeeded in generating a first ECV soil moisture data set. This data set will be released in April 2012 and can be obtained for free for research purposes. This effort will be continued and intensified within the framework of the Climate Change Initiative (CCI) programme of ESA (http://www.esa-cci.org/). In particular the CCI Soil Moisture project will aim to involve a broad scientific community to ensure that the ECV production follows best practices and standards and that the ECV data set meets the requirements of the climate user community. New soil moisture data sets produced with improved algorithms and/or derived from new satellite missions (AMSR 2, SMOS, SMAP, Aquarius, etc.) will be integrated, step by step, in the ECV production process. For example, drawing upon the results achieved within the framework of the ESA funded SMALT project, also soil moisture data derived from nadir-looking active microwave sensors (radar altimeters) may be used as input in the ECV production process. Validation of the data will significantly benefit from the increasing number of in-situ soil moisture networks, many of which are thankfully participating in the International Soil Moisture Network initiative (http://www.ipf.tuwien.ac.at/insitu/) (Dorigo et al., 2011).

\section{REFERENCES}

Albergel, C., de Rosnay, P., Gruhier, C., Muñoz-Sabater, J., Hasenauer, S., Isaksen, L., Kerr, Y. and W., W., 2012. Evaluation of remotely sensed and modelled soil moisture products using global ground-based in situ observations. Remote Sensing of Environment, 118, pp. 215-226.

Albergel, C., Zakharova, E., Calvet, J.C., Zribi, M., Pardé, M., Wigneron, J.P., Novello, N., Kerr, Y., Mialon, A. and Fritz, N.E.D., 2011. A first assessment of the SMOS data in southwestern France using in situ and airborne soil moisture estimates: The CAROLS airborne campaign. Remote Sensing of Environment, 115(10), pp. 2718-2728.

Bartalis, Z., Wagner, W., Dorigo, W. and Naeimi, V., 2010. Accuracy and stability requirements of ERS and METOP scatterometer soil moisture for climate change assessment. In: European Space Agency Living Planet Symposium, Bergen, Norway, Vol. SP-686: pp. 7 p.

Bartalis, Z., Wagner, W., Naeimi, V., Hasenauer, S., Scipal, K., Bonekamp, H., Figa, J. and Anderson, C., 2007. Initial soil moisture retrievals from the METOP-A Advanced Scatterometer (ASCAT). Geophy. Res. Lett, 34, pp. L20401.

Brocca, L., Hasenauer, S., Lacava, T., Melone, F., Moramarco, T., Wagner, W., Dorigo, W., Matgen, P., Martínez-Fernández, J., Llorens, P., Latron, J., Martin, C. and Bittelli, M., 2011. Soil moisture estimation through ASCAT and AMSR-E sensors: An intercomparison and validation study accross Europe. Remote Sensing of Environment, 115, pp. 3390-3408.

Crapolicchio, R., Lecomte, P. and Neyt, X., 2004. The Advanced Scatterometer Processing System for ERS Data: Design, Products and Performances. In: ENVISAT \& ERS Symposium, Salzburg, Austria, 6-10 September 2004, Vol.: pp. de Jeu, R., Wagner, W., Holmes, T., Dolman, H., van de Giesen, N.C. and Friesen, J., 2008. Global soil moisture patterns observed by space borne microwave radiometers and scatterometers. Surveys in Geophysics, 29, pp. 399-420.

Dorigo, W.A., Scipal, K., Parinussa, R.M., Liu, Y.Y., Wagner, W., de Jeu, R.A.M. and Naeimi, V., 2010. Error characterisation of global active and passive microwave soil moisture datasets. Hydrology and Earth System Sciences, 14(12), pp. 2605-2616.

Dorigo, W.A., Wagner, W., Hohensinn, R., Hahn, S., Paulik, C., Xaver, A., Gruber, A., Drusch, M., Mecklenburg, S., van Oevelen, P., Robock, A. and Jackson, T., 2011. The International Soil Moisture Network: a data hosting facility for global in situ soil moisture measurements. Hydrology and Earth System Sciences, 15(6), pp. 1675-1698.

Drusch, M., Wood, E. and Gao, H., 2005. Observation operators for the direct assimilation of TRMM microwave imager retrieved soil moisture. Geophysical Research Letters, 32(15), pp. L15403.

Entekhabi, D., Njoku, E.G., O'Neill, P.E., Kellog, K.H., Crow, W.T., Edelstein, W.N., Entin, J.K., Goodman, S.D., Jackson, T.J., Johnson, J., Kimball, J., Piepmeier, J.R., Koster, R., Martin, N., McDonald, K.C., Moghaddam, M., Moran, S., Reichle, R., Shi, J.C., Spencer, M.W., Thurman, S.W., Tsang, L. and Van Zyl, J., 2010a. The Soil Moisture Active Passive (SMAP) mission. Proceedings of the IEEE, 98(5), pp. 704-716.

Entekhabi, D., Reichle, R.H., Koster, R.D. and Crow, W.T., 2010b. Performance metrices for soil moisture retrievals and application requirements. Journal Of Hydrometeorology, 11(3), pp. 832-840.

Entin, J.K., Robock, A., Vinnikov, K.Y., Hollinger, S.E., Liu, S. and Namkhai, A., 2000. Temporal and spatial scales of observed soil moisture variations in the extratropics. Journal of Geophysical Research, 105(D9), pp. 11865-11877.

Gruhier, C., de Rosnay, P., Hasenauer, S., Holmes, T., de Jeu, R., Kerr, Y., Mougin, E., Njoku, E., Timouk, F., Wagner, W. and Zribi, M., 2010. Soil moisture active and passive microwave products: intercomparison and evaluation over a Sahelian site. Hydrology and Earth System Sciences, 14, pp. 141-156.

Hillel, D., 1982. Introduction to Soil Physics. Academic Press, San Diego, 364 pp.

Kerr, Y., Waldteufel, P., Wigneron, J.-P., Delwart, S., Cabot, F., Boutin, J., Escorihuela, M.-J., Font, J., Reul, N., Gruhier, C., Juglea, S.E., Drinkwater, M.R., Hahne, A., Martin-Neira, M. and Mecklenburg, 2010. The SMOS mission: New tool for monitoring key elements of the global water cycle. Proceedings of the IEEE, 98(5), pp. 666-687.

Koster, R.D., Guo, Z., Yang, R., Dirmeyer, P.A., Mitchell, K. and Puma, M.J., 2009. On the Nature of Soil Moisture in Land Surface Models. Journal of Climate, 22(16), pp. 4322-4335.

Legates, D.R., Mahmood, R., Levia, D.F., DeLiberty, T.L., Quiring, S.M., Houser, C. and Nelson, F.E., 2011. Soil 
moisture: A central and unifying theme in physical geography. Progress in Physical Geography, 35(1), pp. 65-86.

Li, L., Gaiser, P.W., Gao, B.-C., Bevilacqua, R.M., Jackson, T.J., Njoku, E.G., Rüdiger, C., Calvet, J.-C. and Bindlish, R., 2010. WindSat global soil moisture retrieval and validation. IEEE Transaction on Geoscience and Remote Sensing, 48(5), pp. 2224-2241.

Liu, Y.Y., Parinussa, R.M., Dorigo, W.A., de Jeu, R.A.M., Wagner, W., van Dijk, A., McCabe, F.M. and Evans, J.P., 2011. Developing an improved soil moisture dataset by blending passive and active microwave satellite-based retrievals. Hydrology and Earth System Sciences, 15(2), pp. 425-436.

Miralles, D.G., Crow, W.T. and Cosh, M.H., 2010. Estimating Spatial Sampling Errors in Coarse-Scale Soil Moisture Estimates Derived from Point-Scale Observations. Journal of Hydrometerology, 11(6), pp. 1423-1429.

Njoku, E.G., Jackson, T.J., Lakshmi, V., Chan, T.K. and Nghiem, S.V., 2003. Soil moisture retrieval from AMSR-E. IEEE Transactions on Geoscience and Remote Sensing, 41(2), pp. 215-229.

Owe, M., de jeu, R. and Holmes, T., 2008. Multisensor historical climatology of satellite-derived global land surface moisture. Journal of Geophysical Research-Earth Surface, 113(F1), pp. F01002.

Reichle, R.H., Koster, R.D., Dong, J. and Berg, A.A., 2004. Global Soil Moisture from Satellite Observation, Land Surface Models, and Ground Data: Implications for Data Assimilation. Journal of Hydrometeorology, 5, pp. 430-442.

Rodell, M., Houser, P.R., Jambor, U., Gottschalck, J., Mitchell, K., Meng, C.J., Arsenault, K., Cosgrove, B., Radakovich, J., Bosilovich, M., Entin, J.K., Walker, J.P., Lohmann, D. and Toll, D., 2004. The Global Land Data Assimilation System. Bulletin of the American Meteorological Society, 85(3), pp. 381-394.

Rüdiger, C., Holmes, T., Calvet, J.-C., de Jeu, R. and Wagner, W., 2009. An intercomparision of ERS-Scat and AMSR-E soil moisture observations with Model Simulations over France. Journal Of Hydrometeorology, 10(2), pp. 431-447.

Scipal, K., Holmes, T., de Jeu, R., Naeimi, V. and Wagner, W., 2008. A possible solution for the problem of estimating the error structure of global soil moisture data sets. Geophysical Research Letters, 35, pp. L24403:1-4.

Scipal, K., Wagner, W., Trommler, M. and Naumann, K., 2002. The global soil moisture archive 1992-2000 from ERS scatterometer data: First results. In: IGARSS 2002, Vol. 3: pp. 1399-1401.

Seneviratne, S.I., Corti, T., Davin, E.L., Hirschi, M., Jaeger, E.B., Lehner, I., Orlowsky, B. and Teuling, A.J., 2010. Investigating soil moisture-climate interactions in a changing climate - a review. Earth-Science Reviews, 99(3-4), pp. 125161.
Su, Z., Dorigo, W., Fernández-Prieto, D., Helvoirt, M.V., Hungershoefer, K., R. de Jeu, R.P., Timmermans, J., Roebeling, R., Schröder, M., Schulz, J., Tol, C.V.d., Stammes, P., Wagner, W., Wang, L., Wang, P. and Wolters, E., 2010. Earth observation Water Cycle Multi-Mission Observation Strategy (WACMOS). Hydrology and Earth System Sciences Discussions, 7, pp. 7899-7956.

Ummenhofer, C.C., England, M.H., McLntosh, P.C., Meyers, G.A., Pook, M.J., Risbey, J.S., Gupta, A.S. and Taschetto, A.S., 2009. What causes southeast Australia's worst droughts? Geophysical Research Letters, 36(4), pp. L04706.

Wagner, W., Naeimi, V., Scipal, K., de Jeu, R. and MartinezFernandez, J., 2007. Soil moisture from operational meteorological satellites. Hydrogeology Journal, 15(1), pp. 121-131.

Wilson, J.J.W., Anderson, C., Baker, M.A., Bonekamp, H., Figa Saldaña, J., Dyer, R.G., Lerch, J.A., Kayal, G., Gelsthorpe, R.V., Brown, M.A., Schied, E., Schutz-Munz, S., Rostan, F., Pritchard, E.W., Wright, N.G., King, D. and Önel, Ü., 2010. Radiometric calibration of the Advanced Wind Scatterometer Radar ASCAT carried on-board the METOP-A satellite. IEEE Transaction on Geoscience and Remote Sensing, 48(8), pp. 3236-3255.

\section{ACKNOWLEDGEMENTS}

The financial support of the European Space Agency (ESA) through the following projects is gratefully acknowledged: CCI Soil Moisture (http://www.esa-cci.org/), WACMOS (http://wacmos.itc.nl/) and SMALT http://www.cse.dmu.ac.uk/ EAPRS/projects_smalt.html). We also would like to thank our colleague Daniel Chung for preparing Figures 4 to 6. 